\title{
THERMAL EXPANSION COEFFICIENTS FOR SEA ICE
}

\author{
By JEROME B. JOHNSON
}

(U.S. Army Cold Regions Research and Engineering Laboratory, Fort Wainwright,

Alaska $99703-7860$, U.S.A.)

and RONALD C. METZNer

(Chugiak High School, Anchorage, Alaska 99501, U.S.A.)

\begin{abstract}
Coefficients of thermal linear expansion were determined for sea ice using a Michelson interferometer. Over a temperature range of $-4^{\circ}$ to $-15^{\circ} \mathrm{C}$, the coefficients varied from $45 \times 10^{-6}$ to $54 \times 10^{-6}{ }^{\circ} \mathrm{C}^{-1}$ for ice with a salinity of $2 \mathrm{ppt}$, and from $33 \times 10^{-6}$ to $53 \times 10^{-6}{ }^{\circ} \mathrm{C}^{-1}$ for ice with a salinity of $4 \mathrm{ppt}$. Initially, warming the sea ice resulted in coefficients that were the same as those for fresh-water ice, within the limits of experimental error. Subsequent sea-ice cooling resulted in coefficients that were initially lower than those for fresh-water ice, but that asymptotically approached the coefficient values for fresh-water ice at colder temperatures. On the second warming and cooling cycle, the coefficients of thermal linear expansion exhibited hysteresis and a decrease in magnitudes. We have also shown that Pettersson's (1883) and Malmgren's (1927) measurements of the thermal volume expansion of sea ice were the result of phase transitions that caused brine expulsion, when air-free sea ice was cooled, and internal porosity increases, when sea ice was warmed.

Our results indicate that Petterson's (1883) and Malmgren's (1927) measurements of the thermal volume expansion of sea ice are in error. Consequently, theoretical descriptions based on their results are incorrect (Anderson, 1960; Zubov and Savelyev (given in Doronin and Kheisin (1977)); Doronin and Kheisin, 1977). Our results for the initial sea-ice warming cycle do agree with Cox's (1983) analysis.
\end{abstract}

\section{INTRODUCTION}

Understanding how sea ice changes volume in response to temperature changes is important in solving a number of ice-engineering and sea-ice geophysics problems. These can include estimating thermal ice movement, thermal ice pressures against offshore structures and internal ice stresses, and thermal cracking of ice sheets. Thermal expansionrelated ice movements of 0.5 and $0.9 \mathrm{~m} \mathrm{~d}^{-1}$ and thermal structural loads of $150 \mathrm{MN}$ have been recorded in sea ice (Strilchuck, 1977; Johnson and others, 1985). Thermal cracking can reduce the bearing capacity of an ice sheet and increase the probability of its break-up during storms. In addition, thermal cracking in ice covers generate high-frequency Arctic ambient noise, $>300 \mathrm{~Hz}$ (Lewis and Denner, 1988), that can interfere with acoustic monitoring programs in the Arctic.

Coefficients for the thermal volume expansion of sea ice were first determined from measurements in the laboratory by Pettersson (1883) and Malmgren (1927) (their methods are discussed in the following section). Field measurements of ice deformation were used to determine the coefficients of thermal linear expansion for sea ice by Legenkov and Uglev (reported by Doronin and Kheisin (1977)) using invar wire and by Ono and Tanuma (1973) using infra-red distance measurements.
Pettersson's (1883) and Malmgren's (1927) measurements indicate that the range of values for the thermal volume expansion coefficients for sea ice is large, compared to fresh-water ice, and can be either negative or positive depending on ice temperature and salinity (Fig. 1). Legenkov and Uglev's measurements indicated that the thermal expansion coefficients for sea ice were several times smaller than those determined under laboratory conditions. They concluded that their measurements were not representative because of the narrow variations in ice temperature, the time lag in temperature change, and salinity differences with depth for the ice flow used in their experiment. These phenomena were thought to cause the lower ice layers to resist the thermal deformation of the upper layers and vice versa (Doronin and Kheisin, 1977). Ono and Tanuma (1973) estimated that the coefficient of thermal linear expansion for sea ice was $30 \times 10^{-6}{ }^{\circ} \mathrm{C}^{-1}$ Their data, however, have a large amount of scatter and cannot be used to determine reliably the coefficients of thermal linear expansion for sea ice.

Pettersson's (1883) and Malmgren's (1927) results were used by Anderson (1960), Zubov and Savelyev (as reported by Doronin and Kheisin (1977)), and Doronin and Kheisin (1977) to develop analytical descriptions of thermal expansion in sea ice. Cox (1983) presented an analytical description, using the phase-change relationships for sea ice, that contradicted the previous results. He concluded that the internal air and brine in sea ice have no effect on thermal expansion. He further concluded that the coefficients of thermal volume expansion for sea ice must be the same as those for fresh-water ice on both warming and cooling.

Pettersson's (1883) values for the thermal volume expansion coefficients for sea ice are widely quoted and are generally considered to be correct (Anderson, 1960; Neumann and Pierson, 1965; Doronin and Kheisin, 1977). Cox's (1983) analytical results, while intuitively reasonable, do not have the supporting experimental measurements needed to demonstrate that his findings are correct and that Pettersson's (1883) and Malmgren's (1927) experimental results are incorrect. In this paper we examine Pettersson's (1883) and Malmgren's (1927) experimental method and explain their results using the phase relations for sea ice. We then report on our preliminary experiments determining the thermal linear expansion and contraction behavior of sea ice upon warming and cooling. Our results are used to calculate thermal linear expansion coefficients for sea ice and to test Cox's (1983) analysis.

\section{PETTERSSON'S AND MALMGREN'S EXPERIMENTAL METHOD AND RESULTS}

Both Pettersson (1883) and Malmgren (1927) were careful and thorough experimentalists. Yet, it is evident that their experiments to determine coefficients of thermal 


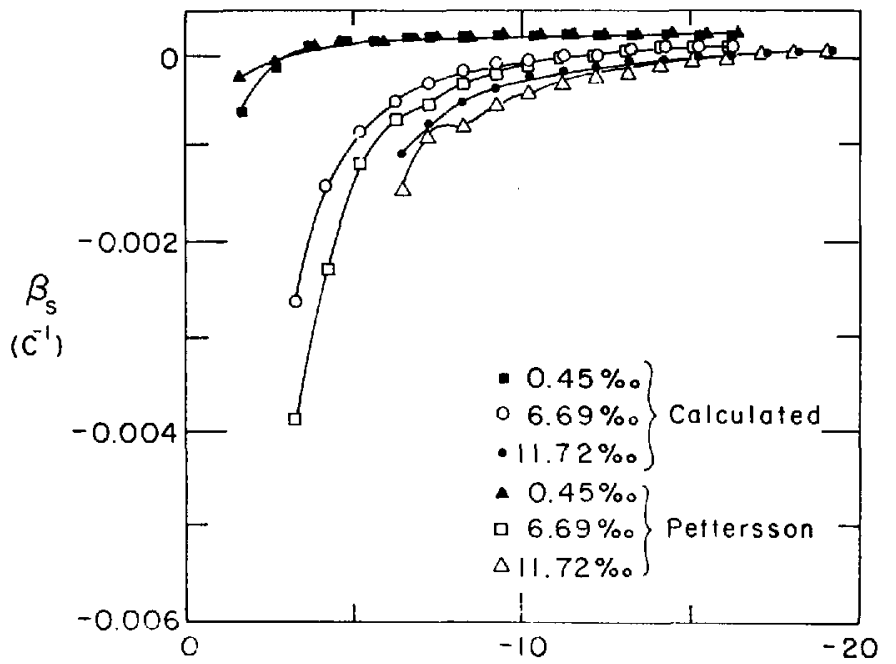

a
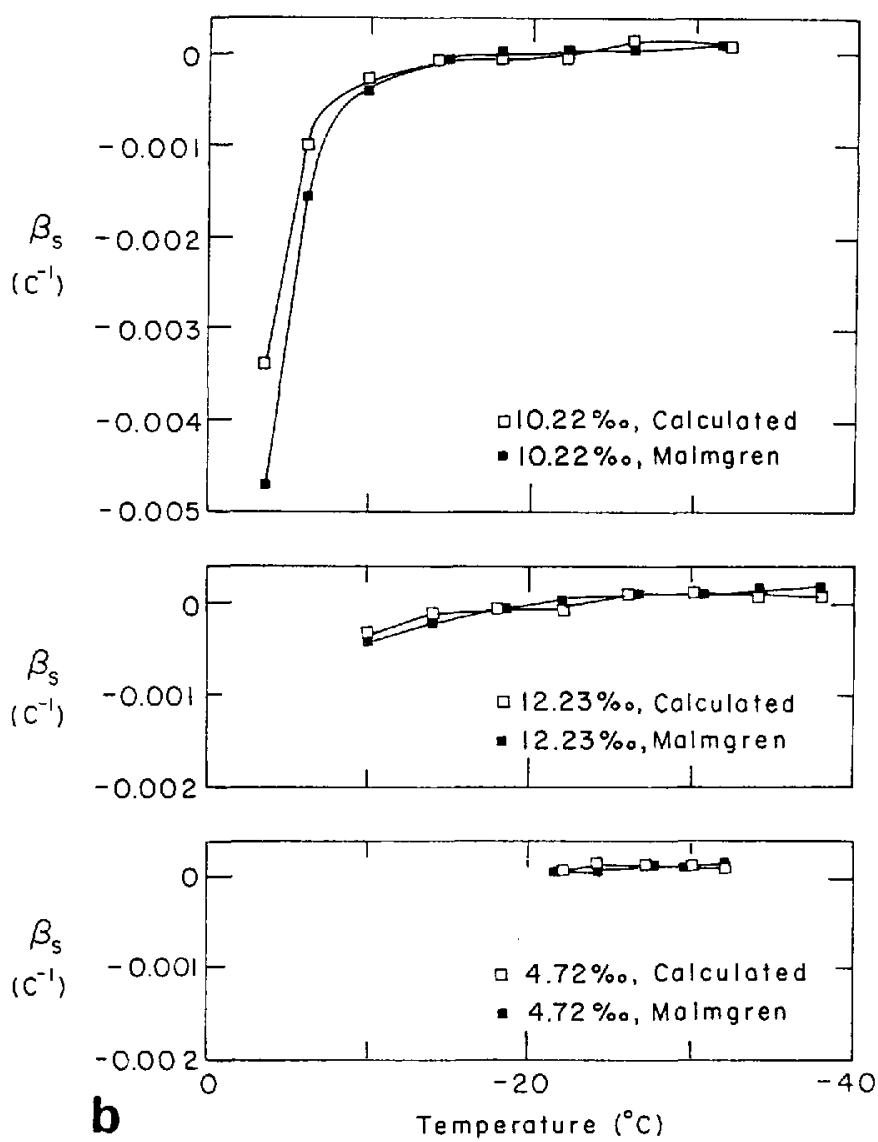

Fig. 1. Comparison of the calculated apparent coefficients of thermal volume expansion for sea ice with the values from (a) Pettersson (1883), and (b) Malmgren (1927).

volume expansion for sea ice were flawed. Pettersson's (1883) and Malmgren's (1927) measurements were made by immersing a sea-ice sample in fluid and then measuring the change in fluid volume as the sample temperature was changed. Fluid-volume changes were then used to calculate thermal volume expansion coefficients for the sample. This procedure assumes that the porosity of the sample remains constant during temperature changes and that no additional fluid is added to the volume of the immersion fluid. Neither of these assumptions is valid when sea ice is the immersed sample. The porosity of sea ice increases when it is warmed and when air-free sea ice is cooled brine will be expelled into the immersion fluid due to phase transitions (Bennington, 1963; Untersteiner, 1968; Cox and Weeks, $1975,1983,1986$ ).

When sea ice is warmed, brine in cavities is diluted by melting the surrounding ice to maintain phase equilibrium.
The phase change and the difference in density between pure ice and brine cause an increase in ice porosity. This porosity increase produces a negative pressure in the internal pore spaces that can draw in fluid surrounding the ice through the interconnected brine-channel system. In the case of Pettersson's (1883) and Malmgren's (1927) experiments, it is the immersion fluid that will be drawn into the sea-ice sample, giving an apparent decrease in volume expansion for the sea ice. This phenomenon will be particularly noticeable at warm temperatures where the brine volume is large. The change in porosity for the sea ice on warming can be determined from

$$
\frac{\mathrm{d} V_{\mathrm{p}}}{\mathrm{d} T}=V_{\mathrm{s}} \beta_{\mathrm{i}}-\left[\frac{\mathrm{d} V_{\mathrm{i}}}{\mathrm{d} T}-\frac{\mathrm{d} V_{\mathrm{b}}}{\mathrm{d} T}\right]
$$

where $V_{\mathrm{p}}$ is the pore-space volume, $T$ is temperature, $V_{\mathrm{S}}=$ $\left(V_{\mathrm{p}}+V_{\mathrm{i}}^{\mathrm{p}}+V_{\mathrm{b}}\right)$ is the bulk volume of the sea ice, $\beta_{\mathrm{i}}^{\mathrm{s}}$ is the coefficient of thermal volume expansion for fresh-water ice, $V_{\mathrm{i}}$ is the volume of the ice matrix, and $V_{\mathrm{b}}$ is the volume of brine. Equation (1) can be written using the phase relations for sea ice as

$$
\frac{\mathrm{d} V_{\mathrm{p}}}{\mathrm{d} T}=\left[\frac{\rho_{\mathrm{i}}}{\rho_{\mathrm{b}}}-1\right] \frac{m_{\mathrm{b}}}{\rho_{\mathrm{b}} S_{\mathrm{b}}} \frac{\mathrm{d} S_{\mathrm{b}}}{\mathrm{d} T}-V_{\mathrm{b}} \frac{\mathrm{d} \rho_{\mathrm{b}}}{\mathrm{d} T}+V_{\mathrm{b}} \beta_{\mathrm{i}}+V_{\mathrm{p}} \beta_{\mathrm{i}}
$$

where $\rho_{\mathrm{i}}$ is the ice density, $\rho_{\mathrm{b}}$ is the density of the brine, $m_{\mathrm{b}}$ is the mass of the brine, and $S_{\mathrm{b}}$ is the brine salinity (Cox, 1983). The change in pore volume is dominated by the phase-change process so that the contribution of thermal volume change by the brine and ice can be neglected giving

$$
\frac{\mathrm{d} V_{\mathrm{p}}}{\mathrm{d} T}=\left[\frac{\rho_{\mathrm{i}}}{\rho_{\mathrm{b}}}-1\right] \frac{m_{\mathrm{b}}}{\rho_{\mathrm{b}} S_{\mathrm{b}}} \frac{\mathrm{d} S_{\mathrm{b}}}{\mathrm{d} T}-V_{\mathrm{b}} \frac{\partial \rho_{\mathrm{b}}}{\partial S_{\mathrm{b}}} \frac{\mathrm{d} S_{\mathrm{b}}}{\mathrm{d} T} .
$$

To examine Pettersson's (1883) and Malmgren's (1927) experiments, we assume that the coefficient of thermal volume expansion of sea ice, $B_{S}$, is the same as that of fresh-water ice, $\beta_{i}$, where

$$
\beta_{\mathrm{s}}=\frac{1}{V_{\mathrm{s}}} \frac{\mathrm{d} V_{\mathrm{s}}}{\mathrm{d} T}
$$

and

$$
\beta_{\mathrm{i}}=\frac{1}{V_{\mathrm{i}}} \frac{\mathrm{d} V_{\mathrm{i}}}{\mathrm{d} T} .
$$

The apparent coefficient of thermal volume expansion for sea ice, $\beta_{a}$, as determined by both Pettersson (1883) and Malmgren (1927) from their experiments, is the difference between the relative volume change due to thermal expansion of the sea ice and the apparent relative volume change caused by drawing immersion fluid into the pore space of the sea ice

$$
\beta_{\mathrm{a}}=\frac{1}{V_{\mathrm{s}}}\left[\frac{\mathrm{d} V_{\mathrm{s}}}{\mathrm{d} T}-\delta \frac{\mathrm{d} V_{\mathrm{p}}}{\mathrm{d} T}\right]
$$

where $\delta$ is the percentage of the created porosity that is filled with immersion fluid.

When air-free sea ice is cooled, the change in the volume of expelled brine as a function of temperature is analogous to the change in porosity of air-free sea ice on warming such that

$$
\frac{\mathrm{d} V_{\mathrm{b}}^{\mathrm{e}}}{\mathrm{d} T}=-\frac{\mathrm{d} V_{\mathrm{p}}}{\mathrm{d} T}+V_{\mathrm{p}} \mathrm{B}_{\mathrm{i}}=-\frac{\mathrm{d} V_{\mathrm{p}}}{\mathrm{d} T}
$$

where $V_{\mathrm{b}}^{\mathrm{e}}$ is the volume of expelled brine (Cox, 1983). The apparent coefficient of thermal volume expansion on cooling is the sum of the relative volume change of the sea ice and the relative volume of expelled brine added to the immersion fluid 


$$
\beta_{\mathrm{a}}=\frac{1}{V_{\mathrm{s}}}\left(\frac{\mathrm{d} V_{\mathrm{s}}}{\mathrm{d} T}+\delta \frac{\mathrm{d} V_{\mathrm{b}}^{\mathrm{e}}}{\mathrm{d} T}\right)
$$

Jsing Equations (3), (4), (5), (6), and (7), and setting $j=1$, we see that the $\beta_{a}$ for air-free sea ice is tpproximately the same for both warming and cooling in ?ettersson's (1883) and Malmgren's (1927) experiments

$$
\beta_{\mathrm{a}} \simeq \beta_{\mathrm{i}}-\left(\frac{\rho_{\mathrm{i}}}{\rho_{\mathrm{b}}}-1\right) \frac{V_{\mathrm{b}}}{V} \frac{\rho_{\mathrm{b}}}{\rho_{\mathrm{i}} S_{\mathrm{b}}} \frac{\mathrm{d} S_{\mathrm{b}}}{\mathrm{d} T}-\frac{V_{\mathrm{b}}}{V} \frac{\partial \rho_{\mathrm{b}}}{\partial S_{\mathrm{b}}} \frac{\mathrm{d} S_{\mathrm{b}}}{\mathrm{d} T}
$$

where $\rho_{\mathrm{b}} V_{\mathrm{b}}$ has been substituted for $m_{\mathrm{b}}$. The variables for Equation (8) are determined from the literature and are jiven in the Appendix.

Figure 1 shows a comparison of Pettersson's (1883) and Malmgren's (1927) values for the coefficients of thermal volume expansion, $\beta_{\text {PMS }}$, with calculated values for the $\beta_{\mathrm{a}}$ 1sing Equation (8). The agreement between the $B_{P M S}$ and he $\beta_{a}$ values is quite good and is consistent with our nterpretation that Pettersson's (1883) and Malmgren's (1927) neasurements are due to phase transition-related porosity ncreases for sea-ice warming and brine expulsion for seace cooling. The results presented in Figure 1 and our nitial assumption that $\beta_{s}=B_{i}$ also indicate that the :oefficients of thermal volume expansion for sea ice, $\beta_{S}$, are imilar to those of fresh-water ice.
COEFFICIENTS OF THERMAL LINEAR EXPANSION FOR SEA ICE

\section{Experimental methods}

We have measured the thermal linear expansion of two congelation sea-ice samples using a Michelson interferometer and a helium-neon laser light source $(632.8 \mathrm{~nm}$ wavelength). An interferometric technique was used because it is a highly accurate method for measuring mechanical displacements and is widely used to measure the thermal linear expansion of solids (Peck and Obetz, 1953; Patten, 1971; Keller and others, 1972; ASTM E 289-70, 1979; Bowles and others, 1981). Interferometry has the added benefit of avoiding the problems associated with the fluid immersion technique used by Pettersson (1883) and Malmgren (1927) to determine the $B_{\mathrm{s}}$.

Our apparatus included the interferometer, cold stage/ sample holder, temperature-control unit, and computercontrolled data-acquisition unit (Fig. 2a). A sea-ice sample with a target mirror frozen to its front surface was housed in a cylindrical holder. The sample and holder were then placed in a urethane-insulated cold stage that constituted one leg of the interferometer. Plastic sheeting was placed under the sea-ice sample to insure that it was not restrained along its bottom edge (Fig. 2b). A few drops of water were used to freeze the bottom back edge of the sample to the holder, eliminating any possiblity of sample movement during a test. Sample temperatures were measured near the
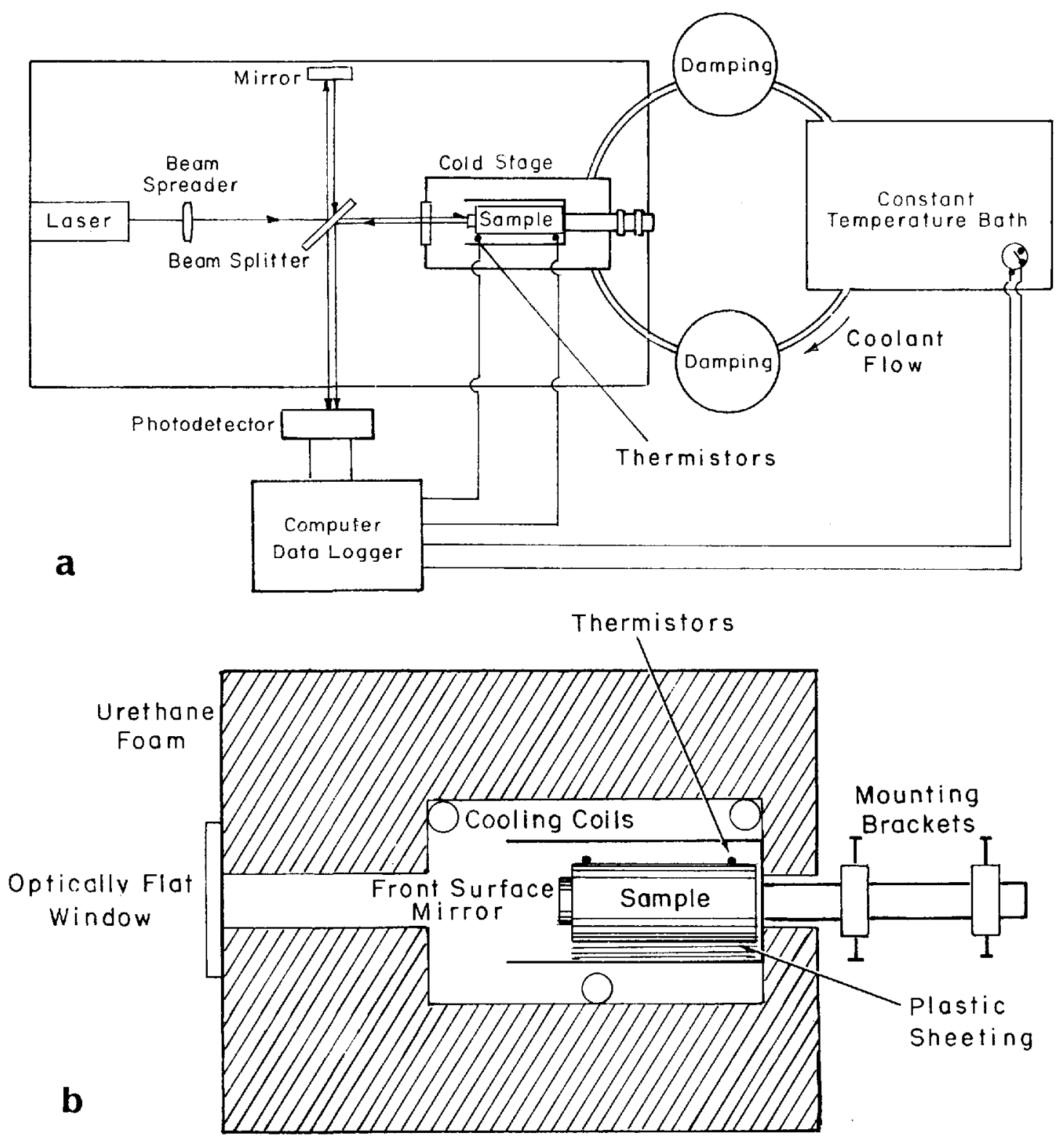

Fig. 2. (a). Michelson interferometer assembly (details of the cold stage are shown in Figure $2 b$ ). Vibrations from the bath's compressor and pump motors, and fluid pressure pulses caused by the pump were attenuated using large damping masses on inlet and outlet cooling tubes and a surge chamber on the cold-stage inlet. (b). Cold stage and fused-quartz sample holder. 
front and back faces of the sample using two thermistors (Fig. 2b). The optically flat, front-surfaced target mirror and sample holder were made from fused quartz, because its coefficient of thermal linear expansion is about two orders of magnitude lower than that of ice $\left(0.37 \times 10^{-6}{ }^{\circ} \mathrm{C}^{-1}\right.$ for fused quartz compared to about $50 \times 10^{-6}{ }^{\circ} \mathrm{C}^{-1}$ for ice). A fused-quartz mounting rod extending from the back of the sample holder through the rear of the cold stage was fixed in place with clamps. The front hole of the cold stage was covered with an optically flat glass window (Fig. 2b).

Sample temperatures were controlled to within $\pm 0.03^{\circ} \mathrm{C}$ by circulating a glycol-water mixture through a precision constant-temperature bath and tubing coil in the cold stage. The cold stage was protected from vibrations caused by the bath's compressor and pump motors by passing the connecting tubes through two large damping masses. Fluid pressure pulses caused by the pump were attenuated using a long, air-filled, sealed coil of copper tubing connected to a $T$ adaptor (surge chamber) on the input line of the cold stage.

An unventilated, insulated room was used to isolate the apparatus from external air-temperature fluctuations, and an oil-bath damping system was used to isolate the apparatus from possible external vibrations.

The two cylindrical sea-ice samples used in the tests were prepared from cores that had been taken from a first-year congelation sea-ice sheet at Harrison Bay, Alaska. Two adjacent ice plugs were removed from the core for each test sample. The first set of ice plugs was cut with their long axes oriented parallel to the ice-sheet surface (that is, perpendicular to the ice-growth direction and in the direction of random ice-crystal $c$-axis orientation. The second set of ice plugs was cut with their long axes in the direction of ice-sheet growth (parallel to the ice-crystal $a$-axes). The first plug from each sample set was used to determine sample salinity before conducting a test; the test sample was made from the second plug. After a test, the sample's salinity was measured (Table I). The front and back faces of the samples were trimmed parallel with a microtome and their lengths determined to within $\pm 0.03 \mathrm{~mm}$ using a dial caliper. Sample lengths were $71.25 \mathrm{~mm}$ for the $2 \mathrm{ppt}$ sea ice and $69.33 \mathrm{~mm}$ for the $4 \mathrm{ppt}$ sea ice. Sample diameters were nominally $38 \mathrm{~mm}$.

Thermal linear expansion of a sample was measured by counting the number of interference fringes that passed a fixed point during a known temperature change. Two photodetectors were placed side by side within the width of a fringe to determine sea-ice displacement magnitude and direction. Figure 3 shows the voltage measurements for each detector from our first test, in which $2 \mathrm{ppt}$ salinity ice was warmed. Each voltage maximum indicates the passage of a fringe; displacement direction is determined from the phase shift between the detectors. For ice expansion, the fringes moved outward and channel 1 detected fringe passage before channel 2. Conversely, channel 1 detected fringe passage after channel 2 when the ice contracted. The passage of one fringe at a fixed point corresponds to a
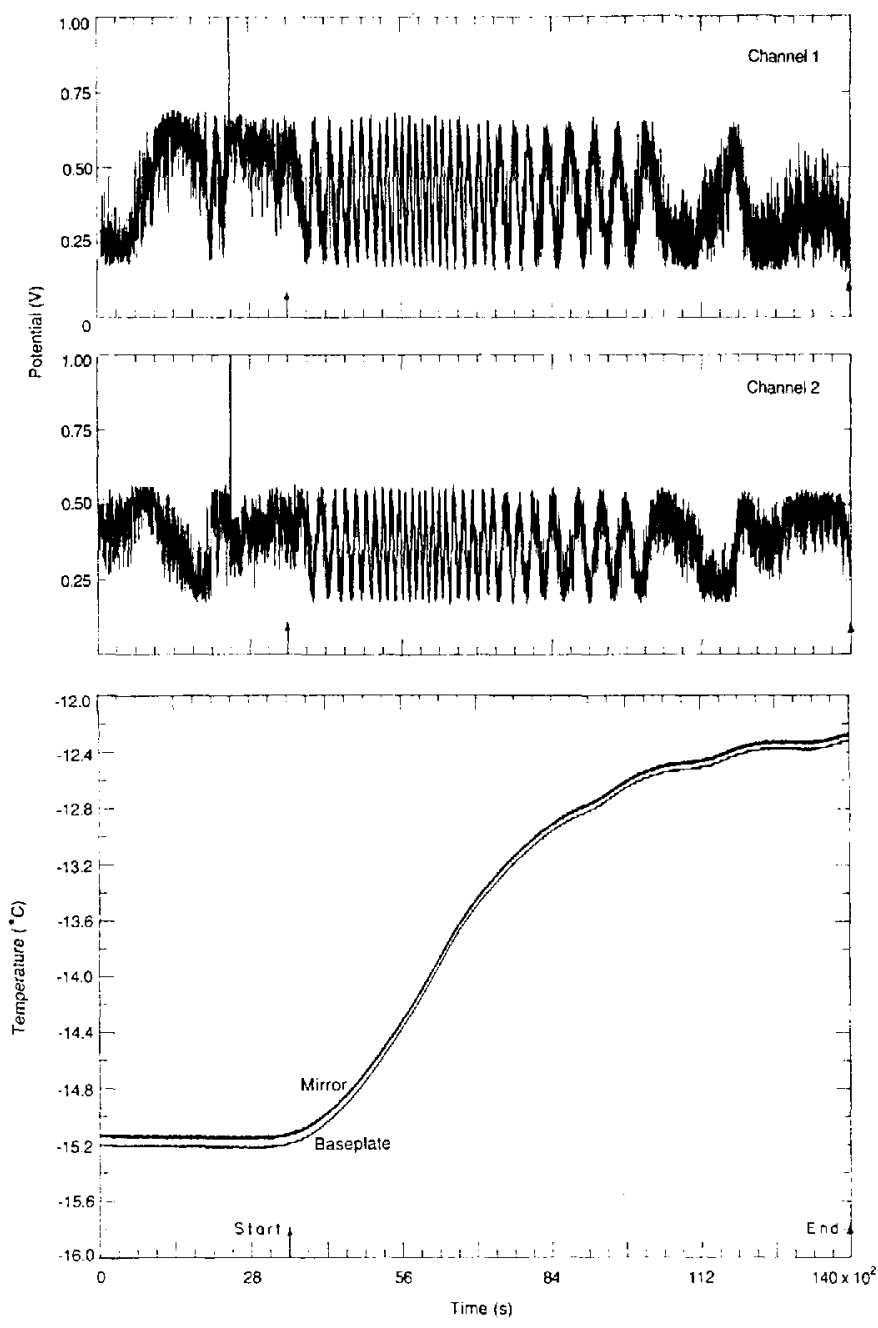

Fig. 3. Output voltage from the two photodetectors and the temperature record for the first warming test on 2 ppt saline ice. The arrows show the start and end times for the test.

TABLE I. THERMAL LINEAR EXPANSION AND COEFFICIENTS OF THERMAL LINEAR EXPANSION FOR SEA ICE

\begin{tabular}{|c|c|c|c|c|c|c|c|}
\hline \multirow[t]{2}{*}{ Ice salinity } & \multirow[t]{2}{*}{ Test type } & & $T$ & $\Delta L / L_{0}$ & $\begin{array}{c}\boldsymbol{B}_{1 \mathrm{~s}} \\
\text { (mean) }\end{array}$ & $T_{\mathrm{m}}$ & $\begin{array}{c}\boldsymbol{\beta}_{1 s} \\
\text { (instantaneous) }\end{array}$ \\
\hline & & & ${ }^{\circ} \mathrm{C}$ & $10^{-5}$ & $10^{-6}{ }^{\circ} \mathrm{C}^{-1}$ & ${ }^{\circ} \mathrm{C}$ & $10^{-6}{ }^{\circ} \mathrm{C}^{-1}$ \\
\hline $\begin{array}{l}\text { Test I } \\
2.2 \mathrm{ppt} \text { before } \\
\text { testing, } 1.4 \mathrm{ppt} \\
\text { after testing }\end{array}$ & Warming & $\begin{array}{r}-15.18 \\
-12.35 \\
-9.33 \\
-7.05 \\
-4.25\end{array}$ & \pm 0.02 & $\begin{array}{cc}0.0 & \\
13.6 & \pm 0.2 \\
30.1 & \pm 0.3 \\
41.2 & \pm 0.4 \\
53.8 & \pm 1.0\end{array}$ & $49.8 \pm 1.4$ & $\begin{array}{l}-13.77 \pm 0.02 \\
-10.79 \\
-8.20 \\
-5.61\end{array}$ & $\begin{array}{l}48.3 \pm 0.8 \\
54.3 \pm 0.8 \\
48.9 \pm 1.0 \\
44.8 \pm 3.3\end{array}$ \\
\hline $\begin{array}{l}\text { Test } 2 \\
4.3 \mathrm{ppt} \text { before } \\
\text { testing, } 3.4 \mathrm{ppt} \\
\text { after testing }\end{array}$ & Warming & $\begin{array}{l}-8.93 \\
-6.39 \\
-3.92\end{array}$ & & $\begin{array}{r}0.0 \\
13.5 \pm 0.9 \\
25.6 \pm 1.3\end{array}$ & $51.2 \pm 3.6$ & $\begin{array}{l}-7.66 \\
-5.19\end{array}$ & $\begin{array}{l}52.9 \pm 3.6 \\
49.4 \pm 3.6\end{array}$ \\
\hline & Cooling & $\begin{array}{r}-6.50 \\
-9.25 \\
-11.91 \\
-14.58\end{array}$ & & $\begin{aligned} 16.1 & \pm 1.6 \\
3.7 & \pm 1.7 \\
-8.4 & \pm 1.9 \\
-21.3 & \pm 1.9\end{aligned}$ & $46.2 \pm 2.6$ & $\begin{array}{r}-5.20 \\
-7.92 \\
-10.60 \\
-13.27\end{array}$ & $\begin{array}{l}36.9 \pm 3.5 \\
45.2 \pm 2.6 \\
45.6 \pm 2.6 \\
48.2 \pm 1.7\end{array}$ \\
\hline & $\begin{array}{l}\text { Second } \\
\text { warming }\end{array}$ & $\begin{array}{l}-9.42 \\
-6.71\end{array}$ & & $\begin{array}{l}0.5 \pm 2.0 \\
9.5 \pm 2.1\end{array}$ & $33.2 \pm 2.6$ & $\begin{array}{r}-10.73 \\
-8.03\end{array}$ & $\begin{array}{l}42.2 \pm 2.6 \\
33.2 \pm 2.6\end{array}$ \\
\hline
\end{tabular}


displacement of one-half the wavelength of $\mathrm{He}-\mathrm{Ne}$ light. In our experiment, the resolution was about $1 / 2$ wavelength $(316.4 \mathrm{~nm})$. However, under ideal conditions, it was possible to resolve displacements to about $1 / 8$ wavelength $(79.1 \mathrm{~nm})$.

Experiments were conducted by first establishing a reference state by maintaining a constant sample temperature until the interference fringes were stationary. Next, the sample temperature was changed to the desired final temperature and held constant until the fringes stopped moving (Fig. 3). For the tests on sea ice, temperatures were changed in steps to insure that the sample was at thermal equilibrium before starting the next temperature change. The number of fringes that passed the photodetectors was counted and the thermal linear expansion was calculated using

$$
\frac{\Delta L}{L_{0}}=\frac{N \lambda}{2 L_{0}}
$$

where $\Delta L$ is the change in sample length, $L_{0}$ is the initial sample length, $N$ is the number of interference fringes, and $\lambda$ is the wavelength of the light source. The instantaneous coefficient of thermal linear expansion, $\beta$, was calculated using

$$
B=\frac{\Delta L}{L_{0} \Delta T} \quad \text { at } \quad T_{\mathrm{m}}=\frac{\left(T_{1}+T_{2}\right)}{2}
$$

where $\Delta L=\left(L_{2}-L_{1}\right), \Delta T=\left(T_{2}-T_{1}\right)$, and $T_{1}$ and $T_{2}$ are the beginning and ending sample temperatures (Touloukian and others, 1975). The accuracy limits of calculating $B$ were estimated by combining the uncertainties of the constituent measurements:

$$
\sigma_{\beta}=\left[\left[\frac{\beta}{\Delta L}\right]^{2} \sigma_{\Delta L}^{2}+\left[\frac{\beta}{L}\right]^{2} \sigma_{L}^{2}+\left[\frac{\beta}{\Delta T}\right]^{2} \sigma_{\Delta T}^{2}\right]^{\frac{1}{2}}
$$

where $\sigma_{\beta}, \sigma_{\Delta L}, \sigma_{L}$, and $\sigma_{\Delta T}$ are the uncertainties in the coefficient of thermal linear expansion, change in sample length, sample length, and the change in sample temperature (Beers, 1957). Values for $\sigma_{\beta}$ are given in Table $\mathbf{I} ; \sigma_{\Delta T}$ was nominally $\pm 0.02^{\circ} \mathrm{C}, \sigma_{L}$ was nominally $\pm 0.03 \mathrm{~mm}$, and $0.30 \mu \mathrm{m}<\sigma_{\Delta L}<0.65 \mu \mathrm{m}$.

The interferometric apparatus was tested by using it to determine the coefficient of thermal linear expansion for Alcoa 6061T6 aluminum alloy bar stock, $B_{A}$. A length of aluminum bar $(70.05 \pm 0.02 \mathrm{~mm})$, with $\mathrm{a}$ target mirror frozen to the bar's front surface, was placed in the sample holder and installed in the cold stage. The thermal linear expansion of the aluminum was determined over a temperature range of $-16.9^{\circ}$ to $-7.52^{\circ} \mathrm{C}$ and used to calculate the $\beta_{\mathrm{A}}$. The $\beta_{\mathrm{A}}$ was $23.6 \pm 0.3 \times 10^{-6}{ }^{\circ} \mathrm{C}^{-1}$ at $-11.8^{\circ} \mathrm{C}$, which compares favorably with the interpolated value of $22.8 \pm 0.7 \times 10^{-6}{ }^{\circ} \mathrm{C}^{-1}$ at $-11.8^{\circ} \mathrm{C}$ determined from the table of recommended values for the $\beta_{A}$ (Touloukian and others, 1975).

\section{Results and discussion}

Our results for $\Delta L / L_{0}$ and $\beta$ are presented in Figures 4 and 5 , and Table $I$. Table $I$ gives values for the mean coefficients of thermal linear expansion for sea ice, $\beta_{\text {Is }}$, and the instantaneous $\beta_{I s}$. The mean $\beta_{I s}$, for each warming and cooling test, is the slope of the best-fit line through the $\Delta L / L_{0}$ values (Fig. 4). There is no temperature-dependence for the mean $\beta_{1 \mathrm{~s}}$, because of the manner of calculation. The instantaneous $\beta_{\mathrm{ls}}$ values are determined from Equation (10).

The mean and instantaneous $B_{15}$ determined for the initial warming of 2 and $4 \mathrm{ppt}$ salinity ice are essentially the same as the values for fresh-water ice published by Butkovich (1959) and Doronin and Kheisin (1977), within the limits of uncertainty for our experiment (Fig. 5). The 4 ppt salinity ice exhibited hysteresis when it was cooled and rewarmed after the initial warming test. A general decrease in magnitude of the mean and instantaneous $\boldsymbol{\beta}_{15}$ was associated with the hysteresis. Butkovich (1959) observed a similar hysteretic behavior for fresh-water ice, in which the coefficients of thermal linear expansion, $\beta_{l i}$, decreased with succeeding runs.

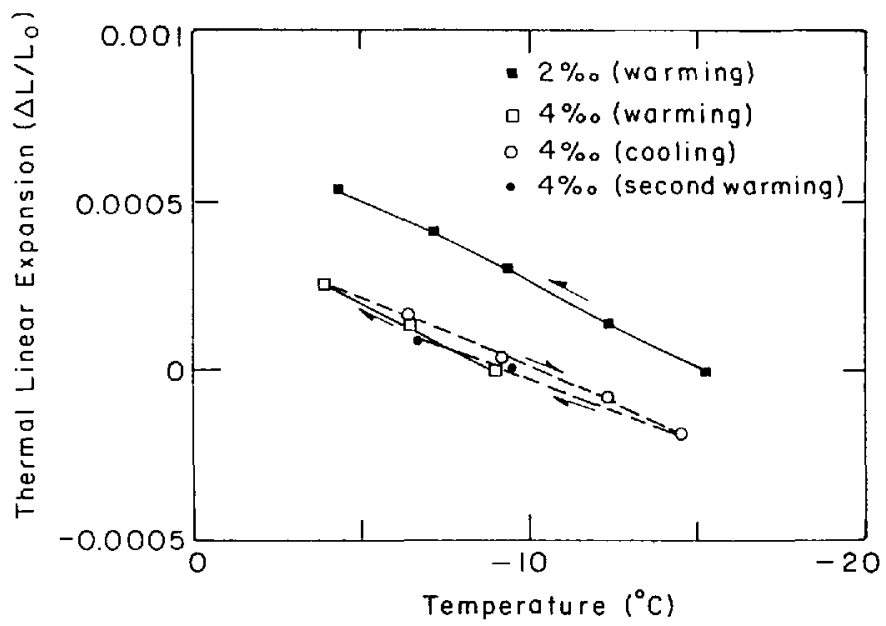

Fig. 4. Thermal linear expansion for sea ice. The arrows show the direction of temperature change during a test.

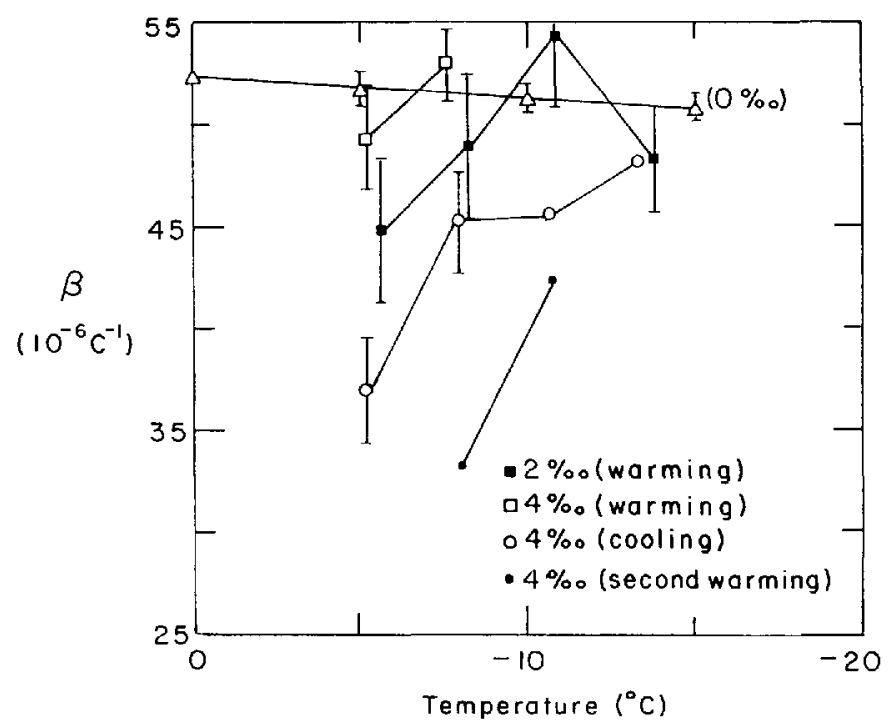

Fig. 5. Instantaneous coefficients of thermal linear expansion for sea ice determined in this study and coefficients of thermal linear expansion for fresh-water ice (Oppt) determined by Butkovich (1959).

Salinity decreased by $0.8 \mathrm{ppt}$ for the $2 \mathrm{ppt}$ salinity ice and $0.9 \mathrm{ppt}$ for the $4 \mathrm{ppt}$ salinity ice during the experiment. These salinity losses were probably caused by brine drainage during the temperature cycles. The amount of salinity change in the samples is too small to affect significantly the phase-change-related processes and are not considered to be important.

A comparison of the $\beta_{1 \mathrm{~s}}$ for the 2 and $4 \mathrm{ppt}$ salinity ice, for the initial warming cycle, with the $B_{l i}$ indicates that they are the same, within the limits of experimental uncertainty. Furthermore, the fact that $c$-axis orientations for the two sea-ice samples were different indicates that the $B_{\text {ls }}$ has little or no dependence on ice-crystal-axis orientation. This means that coefficients for thermal volume expansion can be determined from the $\beta_{1 s}$ using

$$
\beta_{\mathrm{S}}=3 \beta_{1 \mathrm{~s}} .
$$

The observed hysteresis for the $\beta_{1 s}$ may be the result of our experimental technique or may be accounted for by the uncertainty limits of our measurements. However, another possibility is that thermal-history effects on the defect structure induced in the ice could produce the observed hysteresis. For example, dislocations moving under the influence of thermal stresses will have different equilibrium positions upon warming and cooling, thus affecting the microscopic strain to a slight degree (personal communication from D.M. Cole). Further experiments will be needed to examine the causes of hysteresis in the $\beta_{1 s}$. 


\section{Conclusions}

Our analysis of Pettersson's (1883) and Malmgren's (1927) experimental methods shows that their values for the $\beta_{s}$ are incorrect. Their measurements were affected by a phase-transition-related increase in ice porosity when their sea-ice samples were warmed and brine expulsion for sea-ice cooling. Our measurements of sea-ice thermal expansion show that during the initial warming cycle $\beta_{1 s}=$ $\boldsymbol{\beta}_{1 i}$ within the limits of experimental error. Additional temperature cycling of the sea ice shows a slight hysteresis in the $\beta_{1 \mathrm{~s}}$ that may be caused by thermal ice-stress-related dislocation movement. This hysteresis does not affect our conclusion that $\beta_{1 \mathrm{l}}=\beta_{\mathrm{li}}$.

Additional experiments are needed to examine the hysteresis in the $\beta_{1 s}$ with temperature cycling, and to confirm the conclusion that $\beta_{s}=\beta_{i}$ for high-salinity congelation ice and frazil ice.

\section{ACKNOWLEDGEMENTS}

We thank $\mathrm{Mr}$ Berger and the staff at U.S. Army CRREL-Alaska for their help with this project. We also thank Drs Osterkamp, Walker, and Perovich, Mr Ferrick, and an anonymous reviewer for their helpful comments. The archivists at the rare-book section, University of Alaska, Fairbanks, helped us locate Pettersson's original article. We give special thanks to $\mathrm{Mr}$ Matava for writing the dataacquisition and graphics programs, and for running the $4 \mathrm{ppt}$ saline-ice experiments.

Funding for R.C. Metzner was provided by the U.S. Army Summer Fellowship Program for High School Science and Mathematics Faculty.

\section{REFERENCES}

American Society for Testing and Materials. 1982. ASTM standard test method for linear thermal expansion of rigid solids with interferometry. Amm. Book ASTM Standards 41, 316-323.

Anderson, D.L. 1960. The physical constants of sea ice. Research, 13(8), 310-318.

Beers, Y. 1957. Theory of error. Reading, MA, AddisonWesley Publishing Co.

Bennington, K.O. 1963. Some crystal growth features of sea ice. J. Glaciol., 4(36), 669-688.

Bowles, D.E., D. Post, C.T. Herakovich, and D.R. Tenney. 1981. Moiré interferometry for thermal expansion of composites. Exp. Mech., 21(12), 441-448.

Butkovich, T.R. 1959. Thermal expansion of ice. J. Appl. Phys., 30(3), 350-353.

Cox, G.F.N. 1983. Thermal expansion of saline ice. $J$. Glaciol., 29(103), 425-432.

Cox, G.F.N. and W.F. Weeks. 1975. Brine drainage and initial salt entrapment in sodium chloride ice. CRREL Res. Rep. 354.

Cox, G.F.N, and W.F. Weeks. 1983. Equations for determining the gas and brine volumes in sea-ice samples. J. Glaciol., 29(102), 306-316.

Cox, G.F.N. and W.F. Weeks. 1986. Changes in the salinity and porosity of sea-ice samples during shipping and storage. J. Glaciol., 32(112), 371-375.

Doronin, Yu.P. and D.E. Kheisin. 1977. Sea ice. New Delhi, Amerind Publishing Co.

Johnson, J.B., G.F.N. Cox, and W.B. Tucker, III. 1985. Kadluk ice stress measurement program. In POAC 85: the 8th International Conference on Port and Ocean Engineering under Arctic Conditions, Narssarssuaq, Greenland, September 7-14, 1985. Proceedings. Vol. 1. Horsholm, Danish Hydraulic Institute, 88-100.

Keller, R., R. Salathé, and T. Tschudi. 1972. Interferometric measurement of the elongation of a pulsed diode laser. IEEE J. Quantum Electron., QE-8(10), 783-787.

Lewis, J.K. and W.W. Denner. 1988. Higher frequency ambient noise in the Arctic Ocean. J. Acoust. Soc. Am., 84(4), 1444-1445.

Malmgren, F. 1927. On the properties of sea-ice. The Norwegian North Polar Expedition with the "Maud", 1918-1925. Scientific Results, 1(5).
Neumann, G. and W.J. Pierson, jr. 1965. Principles of physical oceanography. Englewood Cliff, NJ Prentice-Hall.

Ono, N. and K. Tanuma. 1973. Strain measurements on pack-ice floe with infra-red distancer. Low Temp. Sci., Ser. A 31, 221-229.

Patten, R.A. 1971. Michelson interferometer as a remote gauge. Appl. Opt., 10(12), 2717-2721.

Peck, E.R. and S.W. Obetz. 1953. Wavelength or length measurement by reversible fringe counting. J. Opt. Soc. Am., 43(6), 505-509.

Pettersson, O. 1883. On the properties of water and ice. In Nordenskiöld, A.E., ed. Vega-expeditionens vetenskapliga iakttagelser. $B d$. 2. Stockholm, F. and G. Beijers Förlag, 247-323.

Pounder, E.R. 1965. The physics of ice. Oxford, etc., Pergamon Press.

Strilchuck, A.R. 1977. Ice pressure measurements, Netserk F-40, 1975-76. APOA Project No. 105-1.

Touloukian, Y.S., R.K. Kirby, R.E. Taylor, and P.D. Desai, eds. 1975. Thermophysical properties of matter. Vol. 12 . Thermal expansion of metallic elements and alloys. New York, Plenum Publishing Corp.

Untersteiner, N. 1968. Natural desalination and equilibrium salinity profile of perennial sea ice. J. Geophys. Res. 73(4), 1251-1257.

Weeks, W.F. 1962. Tensile strength of $\mathrm{NaCl}$ ice. J. Glaciol., $4(31), 25-52$.

Zubov, N.N. 1945. L'dy Arktiki [Arctic ice]. Moscow, Izdatel'stvo Glavsevmorputi.

\section{APPENDIX}

\section{FORMULAS USED IN CALCULATING EQUATION (8)}

Coefficients of thermal linear expansion and thermal volumetric expansion for fresh-water ice (Butkovich, 1959):

$$
\beta_{\mathrm{li}}\left({ }^{\circ} \mathrm{C}^{-1}\right)=\left(52.52+0.1852 T+0.00885 T^{2}+0.000237 T^{3}\right) \times 10^{-6}
$$

where $T$ is in ${ }^{\circ} \mathrm{C}$. For $B_{i}$ we use

$$
B_{\mathrm{i}}=3 \beta_{1 \mathrm{i}}
$$

since the estimated difference between $c$-axis and $a$-axis thermal expansion is only $1.8 \%$ and was not detected by Butkovich (1959).

Density of fresh-water ice (Pounder, 1965):

$$
\rho_{\mathrm{i}}\left(\mathrm{kg} \mathrm{m}^{-3}\right)=917.0-0.1403 T\left({ }^{\circ} \mathrm{C}\right)
$$

Brine salinity and $\mathrm{d} S_{\mathrm{b}} / \mathrm{d} T$ (Cox and Weeks, 1986):

$$
\begin{gathered}
S_{\mathrm{b}}(\mathrm{pp} t)=a_{0}+a_{1} T+a_{2} T^{2}+a_{3} T^{3} \\
\mathrm{~d} S_{\mathrm{b}} / \mathrm{d} T=a_{1}+2 a_{2} T+3 a_{4} T^{2}
\end{gathered}
$$

where $a_{0}=-3.9921, a_{1}=-22.700, a_{2}=-1.0015$, and $a_{3}=$ -0.019956 for $-1.6 \geqslant T>-22.9^{\circ} \mathrm{C} ; \quad a_{0}=206.24, \quad a_{1}=$ $-1.8907, \quad a_{2}=-0.060868$, and $a_{3}=-0.0010247$ for $-22.9 \geqslant T>-44^{\circ} \mathrm{C}$.

Brine density and $\partial \rho_{\mathrm{b}} / \partial S_{\mathrm{b}}$ (Zubov, 1945): the approximate formula for brine density given by Zubov (1945) does not account for thermal volume expansion of the brine. It describes the brine density as a function of brine salinity at $T=0^{\circ} \mathrm{C}$ (Neumann and Pierson, 1965). This formulation is adequate for our needs as the phasetransition effects are much greater than are the thermal expansion effects.

$$
\begin{aligned}
\rho_{\mathrm{b}}\left(\mathrm{kg} \mathrm{m}^{-3}\right) & =1000+0.8 S_{\mathrm{b}}(\mathrm{ppt}) \\
\partial \rho_{\mathrm{b}} / \partial S_{\mathrm{b}} & =0.8 S_{\mathrm{b}} .
\end{aligned}
$$

Relative brine volume (Cox and Weeks, 1986):

$$
\frac{V_{\mathrm{b}}\left(T_{2}\right)}{V}=\frac{S_{\mathrm{b}}\left(T_{1}\right)}{S_{\mathrm{b}}\left(T_{2}\right)} \frac{\rho_{\mathrm{b}}\left(T_{1}\right)}{\rho_{\mathrm{b}}\left(T_{2}\right)} \frac{V_{\mathrm{b}}\left(T_{1}\right)}{V}
$$


where the initial relative brine volume of the sea ice is taken from Weeks (1962):

$$
\frac{V_{\mathrm{b}}}{V}=\frac{\rho S_{\mathrm{i}}}{\rho_{\mathrm{b}} S_{\mathrm{b}}}
$$

where $S_{\mathrm{i}}$ is the sea-ice salinity and the sea-ice density, $\rho$, is equal to

$$
\rho=\frac{\rho_{\mathrm{i}} \rho_{\mathrm{b}} S_{\mathrm{b}}}{\left(\rho_{\mathrm{b}} s_{\mathrm{b}}-S_{\mathrm{b}}\left(\rho_{\mathrm{b}}-\rho_{\mathrm{i}}\right)\right)} .
$$

MS. received 11 January 1990 and in revised form 8 May 1990 